\title{
Longitudinal associations between built environment characteristics and changes in active commuting
}

\author{
Lin Yang ${ }^{1}$, Simon Griffin ${ }^{1,2}$, Kay-Tee Khaw², Nick Wareham and Jenna Panter ${ }^{1 *}$
}

\begin{abstract}
Background: Few studies have assessed the predictors of changes in commuting. This study investigated the associations between physical environmental characteristics and changes in active commuting.

Methods: Adults from the population-based European Prospective Investigation into Cancer (EPIC)-Norfolk cohort self-reported commuting patterns in 2000 and 2007. Active commuters were defined as those who reported 'always' or 'usually' walking or cycling to work. Environmental attributes around the home and route were assessed using Geographical Information Systems. Associations between potential environmental predictors and uptake and maintenance of active commuting were modelled using logistic regression, adjusting for age, sex and BMI.

Results: Of the 2757 participants (62\% female, median baseline age: 52, IQR: 50-56 years), most were passive commuters at baseline $(76 \%, n=2099)$ and did not change their usual commute mode over 7 years $(82 \%, n=2277)$. In multivariable regression models, participants living further from work were less likely to take up active commuting and those living in neighbourhoods with more streetlights were more likely to take up active commuting (both $p<0.05$ ). Findings for maintenance were similar: participants living further from work (over $10 \mathrm{~km}, \mathrm{OR}: 0.06 ; 95 \%$ Cl: 0.25 to 0.13 ) and had a main or secondary road on route were more likely to maintain their active commuting (OR: $0.52 ; 95 \% \mathrm{Cl}: 0.28$ to 0.98 ). Those living in neighbourhoods with greater density of employment locations were less likely to maintain their active commuting.
\end{abstract}

Conclusions: Co-locating residential and employment centres as well as redesigning urban areas to improve safety for pedestrians and cyclists may encourage active commuting. Future evaluative studies should seek to assess the effects of redesigning the built environment on active commuting and physical activity.

Keywords: Travel, Active commuting, Environment, GIS, Longitudinal, EPIC-Norfolk

\section{Background}

Regular engagement in physical activity is associated with a lower risk of developing cardiovascular disease, diabetes, and some cancers $[1,2]$. Walking and cycling are accessible to the majority and several reviews have highlighted the benefits of these activities for cardiovascular disease (for example $[3,4]$ ). Walking or cycling all or part of the way to work offers a comparatively easy way to integrate exercise into daily life [5]. A metaanalysis of 8 prospective studies with follow up periods

\footnotetext{
* Correspondence: jenna.panter@mrc-epid.cam.ac.uk

${ }^{1}$ MRC Epidemiology Unit \& UKCRC Centre for Diet and Activity Research (CEDAR), University of Cambridge, School of Clinical Medicine, Box 285, Cambridge Biomedical Campus, Cambridge CB2 0QQ, UK

Full list of author information is available at the end of the article
}

of between 5 and 20 years suggested that active commuting was associated with an $11 \%$ reduction in cardiovascular risk [6]. The analysis included a wide range of outcomes such as mortality, incident coronary heart disease, stroke, hypertension and diabetes. Despite the benefits, only $14 \%$ of commuters walked or cycled to work in England and Wales in 2011 [7]. In fact, only $24 \%$ of all trips in the UK were made using active modes, which is lower than many other European countries including Demark (31\%), Germany (32\%) and the Netherlands (47\%) [8].

Several reviews suggest that environmental attributes such as population density, mixed land use, street connectivity, aesthetics and safety were associated with 
adults' walking and cycling for transport [9-12]. Specifically, short commute distance, high street connectivity, living in an urban area and high road density were associated with higher levels of active commuting [9-12]. Importantly, most existing research is predominantly cross-sectional in nature, limiting the causal inferences that can be made. Whilst intervention studies are warranted, it is unclear specifically which attributes of the physical environment should be targeted. Some longitudinal studies have suggested that participants living in more supportive areas for walking or cycling or who reported improvements in convenience for walking or cycling were more likely to report increases in walking and cycling [13-15] or smaller reductions in walking [16]. Another study has suggested that safety is particularly important determinant of changes in active commuting [17]. However, few of these longitudinal studies use objective measures of the environment [13-17].

Understanding the associations between environmental attributes and maintenance as well as uptake of active commuting is essential in order to inform the design of environmental interventions. We therefore aim to contribute to the limited longitudinal evidence in this area by investigating the environmental attributes associated with uptake and maintenance of active commuting over 7 years in a cohort of commuters.

\section{Methods}

\section{Study design and population}

This study uses data from the European Prospective Investigation into Cancer (EPIC) Norfolk cohort. The methods of recruitment, sampling, and overall sample representativeness have been described in detail elsewhere [18]. Briefly, between 1993 and 1997 25,633 adults aged 40-79 were recruited through participating general practices in the county of Norfolk, UK. The study design was approved by Norwich District Health Authority Ethics Committee and all participants provided written informed consent.

Between January 1998 and October 2000, 15,678 (61\%) of the cohort attended a health check and completed the EPIC Physical Activity Questionnaire (EPAQ2), a detailed questionnaire on recreational, occupational, utility and household physical activity [19]. This constituted the baseline for the current analysis. Between October 2006 and February 2007, all participants were re-contacted and invited to complete a follow-up questionnaire.

\section{Active commuting}

At baseline and follow-up, participants were asked to report how often they used four types of travel mode to get to their main job (car, work or public transport, bicycle, or on foot) using the response categories of 'always,' 'usually', 'occasionally', and 'never or rarely'. Those who reported 'always' or 'usually' travelling to work by bicycle or on foot were classified as active commuters. Furthermore, multi-modal commuters who reported 'always' or 'usually' travelling to work by car or public transport and by bicycle or on foot were classified as 'active commuters' in order to capture the active element of their journeys. The remainder were classified as passive commuters. Participants were then classified into one of four groups to describe changes in commute mode: those who switched to active commuting, those who switched to passive commuting, those who remained active commuters and those who remained passive commuters.

\section{Environmental features}

Objective assessments of the environmental characteristics in participant's neighbourhoods and along their routes to work were computed using Geographical Information Systems (GIS). Participants reported their home and work postcode and these were converted into map locations using Address Layer, a dataset that identifies the centre point for all postcodes in the UK [20]. An area of $800 \mathrm{~m}$ around the participants' home location was defined as the neighbourhood environment, which is approximately a 10-min walk. The shortest route was identified between home and work via a modified street network which included pedestrianised streets and footpaths. Table 1 provides an overview of the methods used to derive these characteristics and the classifications used in analysis. These environmental characteristics have been associated with active commuting in previous cross-sectional analyses in this cohort [21].

\section{Covariates}

All covariates were assessed at the initial health check at the time of recruitment. Participants self-reported their date of birth and trained nurses measured height and weight following a standard clinical protocol during a clinic visit. Body mass index (BMI) was calculated as weight $/$ height ${ }^{2}\left(\mathrm{~kg} / \mathrm{m}^{2}\right)$ and categorized to under/normal weight $\left(<25 \mathrm{~kg} / \mathrm{m}^{2}\right)$, overweight $\left(25-30 \mathrm{~kg} / \mathrm{m}^{2}\right)$, and obese $\left(\geq 30 \mathrm{~kg} / \mathrm{m}^{2}\right)$ [22]. Age was categorised as up to 50 years, $50-54$ years and 55 years and over. Social class was based on occupation and classified according to the Registrar General's occupation-based classification scheme [23] (professional, managerial and technical; skilled-manual and non-manual and partly skilled or unskilled). Participants additionally self-reported their marital status (and were classified as married or other), smoking status (current smoker, former smoker or never smoker), and drinking behaviour (and classified as non-drinker, sensible or heavy drinker defined using gender specific cut offs) [24]. 
Table 1 Description and classification of objectively-measured neighbourhood and route environmental characteristics

\begin{tabular}{|c|c|c|}
\hline Environmental features & Description & Classification \\
\hline \multicolumn{3}{|l|}{ Neighbourhood } \\
\hline Urbanization & Urban-rural classification of participants' home location & Urban/rural \\
\hline Road density & Total road lengths divided by neighbourhood area $\left(\mathrm{km} / \mathrm{km}^{2}\right)$ & Quartile \\
\hline Proportion of primary road & Presence of primary road & Yes/No \\
\hline Density of junction & Number of junctions divided by total neighbourhood area & Quartile \\
\hline Effective walkable area (EWA) & Total neighbourhood area divided by the potential walkable area ${ }^{a}$ & Quartile \\
\hline Density of pavement & Area of pavements divided by total road length & Quartile \\
\hline Density of pedestrian infrastructure & Area of pedestrian infrastructure divided by total road length & Quartile \\
\hline Number of streetlight per 100 m & The number of lights divided by road length per $100 \mathrm{~m}$ & Quartile \\
\hline Household Density & Total number of household in the neighbourhood area & Quartile \\
\hline Density of employment locations & Number of employment locations divided by area of neighbourhood per $\mathrm{m}^{2}$ & Quartile \\
\hline Land use mix & Proportion of each land use squared and summed ${ }^{b}$ & Quartile \\
\hline Socioeconomic deprivation & Population weighted scores for neighbourhood & Quartile \\
\hline Crime rate & Total crimes per 1000 population in area of residence of year April 2005 - March 2006 & Quartile \\
\hline Density of RTAs & The number of RTAs 2002-2006 per km of roads & Quartile \\
\hline Density of fatal \& serious RTAs & The number of serious and fatal RTAs 2002-2006 per km of roads & Yes/No \\
\hline Accessible land in neighbourhood & Presence of accessible land (all parts and green spaces) in the neighbourhood & Yes/No \\
\hline Park in neighbourhood & Presence of parks in the neighbourhood & Yes/No \\
\hline Green space in neighbourhood & Presence of green spaces in the neighbourhood & Yes/No \\
\hline \multicolumn{3}{|l|}{ Route } \\
\hline \multirow[t]{3}{*}{ Distance from home to work } & \multirow[t]{3}{*}{ The shortest route between home and work identified via the modified street network } & $<1.5 \mathrm{~km}$ \\
\hline & & $1.5-4 \mathrm{~km}$ \\
\hline & & $4-10$ km \\
\hline Route length ratio & Route length divided by the straight line distance between the home and school & Quartile \\
\hline Main road on route & Presence of primary $(A)$ road as part of route & Yes/No \\
\hline Secondary road on route & Presence of secondary (B) road as part of route & Yes/No \\
\hline Main or Secondary road along route & Presence of primary (A) or secondary (B) road as part of route & Yes/No \\
\hline Number of streetlights along route & The number of streetlights along the route divided by route length per $100 \mathrm{~m}$ & Quartile \\
\hline Route land use mix & Proportion of each land use within $100 \mathrm{~m}$ of route squared and summed & Quartile \\
\hline Density of RTAs along route & The total number of RTAs occurred on route between 2002 and 2005 per km of roads & Quartile \\
\hline Density of fatal \& serious RTAs along route & $\begin{array}{l}\text { The number of fatal and serious RTAs occurred on route between } 2002 \text { and } \\
2005 \text { per km of roads }\end{array}$ & Yes/No \\
\hline
\end{tabular}

\section{RTA Road traffic accidents}

${ }^{\mathrm{a}}$ Total neighbourhood area is the area that can be reached via the street network within $800 \mathrm{~m}$ from the home and the potential walkable area is the area generated using a circular buffer with a radius of $800 \mathrm{~m}$ from the home

${ }^{\mathrm{b}}$ Seventeen different land uses were classified: farmland, woodland, grassland, uncultivated land, other urban, beach, marshland, sea, small settlement, private gardens, parks, residential, commercial, multiple use buildings, other buildings, unclassified buildings and roads. This score is also known as the Herfindahl-Hirschman Index developed by Rodriguez and Song (2005)

\section{Statistical analysis}

Descriptive statistics for participants' socio-demographic characteristics were summarized. Two separate logistic regression models were run to assess i) the odds of taking up active commuting, compared to taking up passive travel, and ii) the odds of maintaining active commuting compared to taking up passive travel.

In univariate analysis, all potential environmental attributes were tested as predictors. Variables were entered into the multiple logistic regression models if they were significant at $p<0.05$ in univariate analyses [25]. If two or more variables were correlated at least $r>0.55$, the variable most strongly associated with the outcome was carried forwards. We assessed the significance of categorical variables by examining tests for trend. In multiple logistic regression models, variables were removed if they did not reach the significance level of $p<0.05$, one at a time, starting with the variable with the highest 
$p$ value. Very few of the socio-demographic characteristics were associated with uptake or maintenance of active commuting (Additional file 1: Table S1) and in general adjustment for these had a small effect on the associations between environmental characteristics and uptake and maintenance. As a result, we chose to adjust our analyses for age, sex and BMI only. All analyses were performed using Stata version 11.0. Although we hypothesised that distance may moderate the associations between environmental predictors and changes in active commuting, the cell sizes for some variables prevented us from formally testing for interactions. Multi-level modelling was not appropriate here as participants were not sampled through postcodes and behaviour was not clustered.

\section{Results}

\section{Sample characteristics}

Of the 15,678 participants who completed EPAQ2 at baseline, 11,009 also returned a questionnaire at followup. For these analyses we excluded those who reported not working at either time point $(n=5063)$, failed to provide information on socio-demographic characteristics at recruitment, failed to provide data on commuting behaviour, or reported long term disability which precluded walking or health conditions $(n=3189)$. This left 2757 participants for analysis. Compared to those excluded from the analysis, those included tended to be younger (52.3 vs $60.6 \mathrm{yrs})$, married (85.8\% vs $83.6 \%$ ) and have a lower BMI $\left(25.8 \mathrm{vs} 26.3 \mathrm{~kg} / \mathrm{m}^{2}\right)$, and were more likely to report having a professional occupation at baseline (all $p<0.03$ ).

Table 2 gives details of the characteristics of the sample and $41 \%$ of participants lived in urban areas. As there were no significant differences in changes in commute mode by sex, we analysed the entire sample as one group. The majority of the sample were passive commuters at baseline $(76 \%, n=1866) .8 \%(n=233)$ of the sample took up active commuting, whilst $14 \%$ maintained their active commuting.

\section{Environmental predictors of uptake of active commuting}

In the overall sample, 18 environmental characteristics predicted uptake of active commuting $(p<0.05$, Additional file 2: Table S2). Although it is difficult to compare the effect sizes between attributes measured using different scales, measures of street density (e.g. density of junctions and roads), infrastructure for pedestrians (e.g. pavements in the neighbourhood and streetlights along the route), safety (e.g. street lighting), traffic (e.g. road traffic accidents) and density of destinations were all associated with uptake. In final adjusted models, only three significant results remained: those whose routes to work were longer or included a main or secondary road were less likely to take up active commuting (over $10 \mathrm{~km}$
Table 2 Descriptive characteristics of participants in the EPIC-Norfolk cohort included in the analyses comparing men and women

\begin{tabular}{|c|c|c|c|}
\hline & Men & Women & $P$ \\
\hline & $n=438$ & $n=705$ & \\
\hline \multicolumn{4}{|l|}{ Age (in years) } \\
\hline$<50$ & $116(26.5 \%)$ & $266(37.7 \%)$ & \multirow[t]{3}{*}{$<0.001$} \\
\hline $50-54$ & $172(39.2 \%)$ & $264(37.5 \%)$ & \\
\hline$>=55$ & $150(35.3 \%)$ & $175(24.8 \%)$ & \\
\hline \multicolumn{4}{|l|}{ BMI (kg/m2) } \\
\hline Normal weight & $150(34.3 \%)$ & $383(54.33)$ & \multirow[t]{3}{*}{$<0.001$} \\
\hline Overweight & $243(55.5 \%)$ & $211(31.4 \%)$ & \\
\hline Obese & $45(10.3 \%)$ & $101(14.3 \%)$ & \\
\hline \multicolumn{4}{|l|}{ Social Class } \\
\hline Professional & $219(50.0 \%)$ & $287(40.7 \%)$ & \multirow[t]{3}{*}{0.008} \\
\hline Skilled & $159(36.3 \%)$ & $311(44.1 \%)$ & \\
\hline Partly Skilled/unskilled & $60(13.7 \%)$ & $107(15.2 \%)$ & \\
\hline \multicolumn{4}{|l|}{ Marital Status } \\
\hline Not married & $34(7.8 \%)$ & $129(18.3 \%)$ & \multirow[t]{2}{*}{$<0.001$} \\
\hline Married & $404(92.2 \%)$ & $576(81.7 \%)$ & \\
\hline \multicolumn{4}{|l|}{ Alcohol Consumption } \\
\hline Non drinker & $19(4.3 \%)$ & $58(8.2 \%)$ & \multirow[t]{3}{*}{0.008} \\
\hline Sensible drinker & 357 (81.5\%) & $575(81.6 \%)$ & \\
\hline Heavy drinker & $62(14.2 \%)$ & $72(10.2 \%)$ & \\
\hline \multicolumn{4}{|l|}{ Smoking Status } \\
\hline Never smoke & $212(48.4 \%)$ & 416 (59.0\%) & \multirow[t]{3}{*}{$<0.001$} \\
\hline Former smoker & $194(44.3 \%)$ & $223(31.6 \%)$ & \\
\hline Current smoker & $32(7.3 \%)$ & $66(9.4 \%)$ & \\
\hline \multicolumn{4}{|l|}{ Change of commuting ${ }^{a}$} \\
\hline Non-AC to non-AC & $265(60.5 \%)$ & 412 (58.4\%) & \multirow[t]{4}{*}{0.450} \\
\hline Non-AC to $A C$ & 49 (11.2\%) & 66 (9.4\%) & \\
\hline$A C$ to $A C$ & $86(19.6 \%)$ & $163(23.1 \%)$ & \\
\hline$A C$ to non-AC & $38(8.7 \%)$ & $64(9.1 \%)$ & \\
\hline
\end{tabular}

${ }^{\mathrm{a}} \mathrm{AC}$ if the participant engaged in active commuting on their journey to and from work, non- $\mathrm{AC}$ if the participant did not engage in active commuting on their journey to and from work. Data are $\mathrm{n}$ (proportion in \%) unless specified.

OR: 0.04 ; $95 \%$ CI: 0.02 to 0.09 ; main road: OR: 0.45 ; $95 \%$ CI: 0.25 to 0.79 ) and those whose routes to work had more streetlights (highest quartile (OR: 3.98; 95\% CI: 1.85 to 8.57 ) were more likely to take up active commuting (Table 3).

\section{Environmental predictors of maintenance of active commuting}

In general, fewer environmental features were associated with maintenance of active commuting than uptake. Ten environmental features predicted maintenance of active commuting with $p<0.05$ (Additional file 2, Table S2). In final adjusted models, results indicate that those who 
Table 3 Crude and adjusted odds ratio in simple and multiple logistic regression analyses of the association between neighbourhood and route environment characteristics and change in commuting mode stratified by commuting modes at baseline, with adjustment for age, sex and BMI

\begin{tabular}{|c|c|c|c|c|c|c|c|c|}
\hline & \multicolumn{4}{|c|}{ Uptake of active commuting } & \multicolumn{4}{|c|}{ Maintenance of active commuting } \\
\hline & Model a & $p$ & Model b & $p$ & Model a & $p$ & Model b & $p$ \\
\hline & OR $(95 \% \mathrm{Cl})$ & & OR $(95 \% \mathrm{Cl})$ & & OR $(95 \% \mathrm{Cl})$ & & OR $(95 \% \mathrm{Cl})$ & \\
\hline \multicolumn{9}{|c|}{ Neighbourhood Environment } \\
\hline \multicolumn{9}{|c|}{ Effective walkable area (EWA) (Reference: Lowest) } \\
\hline Second quartile & & & & & $0.69(0.36-1.31)$ & 0.02 & $0.62(0.30-1.29)$ & 0.02 \\
\hline Third Quartile & - & - & - & - & $0.85(0.44-1.63)$ & & $0.75(0.35-1.60)$ & \\
\hline Highest & - & - & - & - & $0.43(0.22-0.82)$ & & $0.32(0.15-0.68)$ & \\
\hline \multicolumn{9}{|l|}{ Route Environment } \\
\hline \multicolumn{9}{|c|}{ Distance from home to work (Reference: $<1.5 \mathrm{~km}$ ) } \\
\hline $1.5-4 \mathrm{~km}$ & $0.31(0.19-0.52)$ & $<0.001$ & $0.23(0.13-0.39)$ & $<0.001$ & $2.94(1.59-5.42)$ & $<0.001$ & $2.85(1.45-5.59)$ & $<0.001$ \\
\hline $4-10 \mathrm{~km}$ & $0.08(0.04-0.13)$ & & $0.06(0.03-0.11)$ & & $8.34(4.33-16.10)$ & & $8.82(4.15-18.80)$ & \\
\hline \multicolumn{9}{|c|}{$\begin{array}{l}\text { Main or secondary road on route } \\
\text { (Reference: No) }\end{array}$} \\
\hline Yes & - & - & - & - & $2.71(1.56-4.69)$ & $<0.001$ & $1.97(1.04-3.73)$ & 0.04 \\
\hline \multicolumn{9}{|c|}{$\begin{array}{l}\text { Number of streetlights per } 100 \text { m } \\
\text { (Reference: Lowest) }\end{array}$} \\
\hline Second quartile & $3.54(1.83-6.86)$ & $<0.001$ & $2.54(1.24-5.21)$ & $<0.001$ & - & - & - & - \\
\hline Third Quartile & $2.26(1.12-4.58)$ & & $2.04(0.95-4.39)$ & & - & - & - & - \\
\hline Highest & $4.77(2.46-9.24)$ & & $5.45(2.62-11.33)$ & & - & - & - & - \\
\hline
\end{tabular}

Model a: Univariate associations

Model b: Adjusted for baseline age, sex and BMI as well as other environmental predictors listed

lived in areas with a greater density of employment locations were more likely to maintain their active commuting (highest quartile OR: 3.13; 95\% CI: 1.48 to 6.64). Those with longer routes to work (over $10 \mathrm{~km}$, OR: 0.06; $95 \%$ CI: 0.25 to 0.13 ) and a main or secondary road on their route were less likely to maintain their active commuting (OR: 0.52; 95\% CI: 0.28 to 0.98; Table 3).

\section{Discussion}

\section{Principal findings}

This study provides new evidence on the environmental attributes associated with uptake and maintenance of active commuting in adults. In general, we found that supportive environments predicted uptake of active commuting: those living further from work and who had a main or secondary road on their route were less likely to take up and maintain their active commuting. Those with routes to work with more streetlights were more likely to take up active commuting and those who lived in areas with a higher density of employment locations were more likely to maintain their active commuting.

\section{Strengths and limitations}

To the best of our knowledge, this is one of the few studies to investigate the associations between characteristics of the physical environment and changes in active commuting in adults. We use objective measures of the environment and data on commuting from a wellcharacterised cohort of working adults living in both urban and rural areas which provides environmental heterogeneity. The GIS data were collected before the follow-up period but we are not aware of any major physical environment changes which occurred during the study period, although we acknowledge that there may have been changes in crime rates, traffic volumes and public transport provision during this time. Our measures also considered features of the neighbourhood and route environment. The former were specific to each individual and did not rely on pre-defined neighbourhood areas. Our assessments of the route environment used the shortest route between home and work and these may not represent the actual routes participants used. We have no information on why residents choose to live in particular residential areas and therefore were unable to control for residential self-selection [26]. We do not know whether work locations changed over time as this information was not collected at both time points and no information was available on the characteristics of workplace environments but these would be valuable additions to future studies aiming to understand the role of the environment in shaping changes in active commuting behaviour. 
Uptake and maintenance of active commuting were defined using data on habitual commute mode in 2000 and 2007, and we acknowledge there may have been some changes in active commuting behaviours between these time points which we could not capture. In addition, we had no information on the duration or intensity of activity on the commute. We ensured that those who reported always active commuting, even if it was in combination with passive modes of transport were included as it is known that these short bouts of activity can add up to a substantial amount over the course of a week $[27,28]$. One study using an objective assessment of activity found that over the course of a week $80 \%$ of the journey time on a walking or cycling journey is spent at moderate or vigorous intensity. Even for an $8 \mathrm{~min}$ journey, this could amount to over half the recommended levels of physical activity for adults over the course of a working week [28]. Previous studies [9] suggest that environmental features might be differentially associated with walking and cycling. However, in our sample relatively small numbers of participants had changed their usual commute modes, and hence we were unable to explore any potential differences between walking and cycling. Although the study sample are drawn from Norfolk which is a largely rural county with predominantly White population and the majority of whom own a car [8], our sample of healthy, working adults represents a key target group for health promotion.

\section{Comparison with the existing literature}

In our analyses, distance from home to work demonstrated the strongest association with changes in commuting behaviour, which is in line with previous findings [9-17]. We also found that participants living in neighbourhoods with higher numbers of streetlights were more likely to take up active commuting. Well-lit routes may have lower levels of perceived crime and be perceived as safer places to walk. Interestingly crime rates were significantly associated in univariate models but did not remain significant in maximally adjusted models. As such it may be that perceptions of crime rather than actual levels are more important in determining behaviour. Recent studies suggest that increases in resident's perceptions of fear of crime were associated with decreases in levels of walking [29] and increases in perceived danger for pedestrians and cyclists were associated with increases in car use [13], although others have found no associations between changes in perceptions of safety and walking [30]. However, the best way to reduce fear of and perceived risk from crime is unknown, and this is likely to be sensitive to time, location and social context [31].

We also found participants living in neighbourhoods with a greater density of employment locations were more likely to maintain their active commuting. These findings suggest that co-locating residential and employment areas together will reduce the distance required to travel and therefore encourage active commuting. Whilst we assessed multicollinearity between micro-environmental variables and larger macro-environmental variables such as urban rural status, we carried forward the one which was most strongly related with our outcomes. Even after adjustment for urban rural status, the associations between environmental characteristics and change in active commuting persisted (results not shown). Although cross-sectional studies have also suggested that factors such as connected street networks and high road density are important influences on behaviour [10-13], other factors may act as a barrier to maintenance. We did not have information on changes family circumstances or changing financial or personal situations which have been shown to influence travel behaviour [32].

\section{Implications and further research}

The low prevalence of active commuting in several developed countries [8] suggests that there is a potential to increase cycling and walking behaviour as means of commuting and our findings suggest avenues for intervention which may be effective and should be the focus of future evaluations. Distance from home to work was the strongest predictor of uptake and maintenance of active commuting and local planners may be able to colocate new residential developments and workplaces, thus reducing the distances required to travel to work. In addition, promoting the use of existing off-site car parks and encouraging short walking or cycling trips from these sites may also be beneficial in terms of accumulating physical activity [27] and improving well-being [33].

Our findings also suggest that higher levels of streetlight provision were associated with uptake of active commuting. Systematic reviews have found some evidence that increased street lighting may lead to improved road safety [34] and overall reductions in crime [35]. Micro-level infrastructure improvements such as street lighting may promote active commuting; however, the mechanisms between safety concerns and activity should be examined in further research. We suggest that perceptions of environment might mediate the association between objective assessment of the physical environment and changes in active commuting and this should be an avenue for future research.

\section{Conclusions}

In this longitudinal study, we found some support for a limited number of potential determinants of changes in active commuting described in the cross-sectional literature. Macro-level changes, such as the redevelopment or regeneration of whole urban areas as well as microscale changes at the street level, such as the street 
lighting may be effective. The effects of these improvements on behaviour needs to be examined in formal evaluative studies, preferably incorporating psychological factors along with environment factors to examine mechanisms underlying the change and maintenance of commuting behaviour.

\section{Additional files}

Additional file 1: Table S1. Results table for univariate associations between sociodemographic characteristics and uptake and maintenance of active commuting. (DOCX $18 \mathrm{~kb}$ )

Additional file 2: Table S2. Description of data: Results table for univariate associations between environmental predictors and uptake and maintenance of active commuting. (DOCX 28 kb)

\section{Abbreviations}

BMI: Body mass index; EPAQ2: EPIC Physical Activity Questionnaire; EPIC: European Prospective Investigation into Cancer; GIS: Geographical Information Systems

\section{Acknowledgements}

We thank all the EPIC Norfolk staff and participants for their invaluable contributions.

\section{Competing interest}

All authors declare they have no competing interest.

\section{Consent to publication}

Not applicable.

\section{Funding}

The EPIC-Norfolk study is supported by programme grants from the Medical Research Council (G1000143) and Cancer Research UK (C864/A14136), with additional support from the Stroke Association, British Heart Foundation, Research Into Ageing, and the Academy of Medical Science. The funding body had no role in the design of the study and collection, analysis, and interpretation of data or in writing the manuscript.

\section{Availability of data and materials}

The datasets used during the current study are available from the corresponding author on reasonable request.

\section{Author's contributions}

LY, SG and JP specified the research question and analysis. LY and JP executed the analysis, LY, SG and JP interpreted the data and LY and JP drafted the manuscript. NJW and KTK are investigators of the EPIC-Norfolk study and were responsible for data collection and study design. All contributed critical input and approved the final version to be published.

\section{Ethics approval and consent to participate}

The study design was approved by Norwich District Health Authority Ethics Committee and all participants provided written informed consent.

\section{Publisher's Note}

Springer Nature remains neutral with regard to jurisdictional claims in published maps and institutional affiliations.

\section{Author details}

${ }^{1}$ MRC Epidemiology Unit \& UKCRC Centre for Diet and Activity Research (CEDAR), University of Cambridge, School of Clinical Medicine, Box 285, Cambridge Biomedical Campus, Cambridge CB2 0QQ, UK. '²epartment of Public Health and Primary Care, School of Clinical Medicine, Box 285, Cambridge Biomedical Campus, Cambridge CB2 OSR, UK.
Received: 9 January 2017 Accepted: 8 May 2017

Published online: 17 May 2017

\section{References}

1. Haskell WL, Lee IM, Pate RR, et al. Physical activity and public health: updated recommendation for adults from the American College of Sports Medicine and the American Heart Association. Med Sci Sports Exerc. 2007 39(8):1423-34

2. Reiner M, Niermann C, Jekauc D, Woll A. Long-term health benefits of physical activity - a systematic review of longitudinal studies. BMC Public Health. 2013;13(1):813

3. Sattelmair J, Pertman J, Ding EL, Kohl HW, Haskell W, Lee I-M. Dose Response Between Physical Activity and Risk of Coronary Heart Disease. Circualtion. 2011;124:789-95.

4. Saunders LE, Green JM, Petticrew MP, Steinbach R, Roberts H. What Are the Health Benefits of Active Travel? A Systematic Review of Trials and Cohort Studies. PLoS One. 2013;8(8):e69912. doi:10.1371/journal.pone.0069912.

5. Shepherd RJ. Is active commuting the answer to population health? Sports Med. 2008;38(9):751-8

6. Hamer M, Chida Y. Active commuting and cardiovascular risk: a metaanalytic review. Prev Med. 2008;46:9-13.

7. Office of National Statistics. Neighbourhood Statistics Census. 2011. [Accessed 12 May 2017]. Available from: https://www.nomisweb.co.uk/.

8. Bassett DR, Pucher J, Buehler R, Thompson DL, Crouter SE. Walking, Cycling, and Obesity Rates in Europe, North America, and Australia. J Phys Act Health. 2008:5:795-814.

9. Saelens BE, Sallis JF, Frank L. Environmental correlates of walking and cycling: findings from the transportation, urban design, and planning literatures. Ann Behav Med. 2003;25(2):80-91.

10. Panter JR, Jones A. Attitudes and the environment as determinants of active travel in adults: what do and don't we know? J Phys Act Health. 2010;7(4): 551-61

11. Van Holle DB, Van Cawenberg J, Goubert L, Maes L, Van de Weghe N, de Bourdeaudhuij I. Relationship between the physical environment and different domains of physical activity in European adults: a systematic review. BMC Public Health. 2012;12(1):807

12. Humpel N, Owen N, Leslie E. Environmental factors associated with adult's participation in physical activity: a review. Am J Prev Med. 2002;22:188-99.

13. Panter J, Griffin S, Ogilvie D. Active commuting and perceptions of the route environment: A longitudinal analysis. Prev Med. 2014;67:134-40.

14. Humpel N. Changes in neighborhood walking are related to changes in perceptions of environmental attributes. Ann Behav Med. 2004;27(1):60-7.

15. Sugiyama T, Shibata A, Koohsari MJ, Tanamas SK, Oka K, Salmon J, Dunstan DW, Owen N. Neighborhood environmental attributes and adults' maintenance of regular walking. Med Sci Sport Exerc. 2015:47:1204-10.

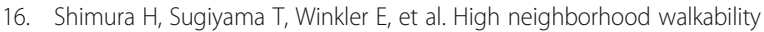
mitigates declines in middle-to-older aged adults' walking for transport. J Phys Act Health. 2012;9(7):1004-8.

17. Panter J, Griffin S, Dalton A, Ogilvie D. Patterns and predictors of changes in active commuting to work over 12 months. Prev Med. 2013:57(6):776-84.

18. Day N, Oakes S, Luben R, et al. EPIC-Norfolk: study design and characteristics of the cohort. European Prospective Investigation of Cancer. Br J Cancer. 1999;80(Suppl 1):95-103

19. Wareham NJ, Jakes RW, Rennie KL, et al. Validity and repeatability of the EPIC-Norfolk Physical Activity Questionnaire. Int J Epidemiol. 2002;31(1): 168-74.

20. Ordnance Survey. OS MasterMap Address Layer. 2006 [cited 2015 Nov 1]. Available from: https://www.ordnancesurvey.co.uk/business-andgovernment/help-and-support/products/addresslayer2.html.

21. Panter JR, Jones AP, van Sluijs EM, et al. Environmental and psychological correlates of older adult's active commuting. Med Sci Sports Exer. 2011; 43(7):1235-43.

22. World Health Organisation. Obesity: preventing and managing the global epidemic. In: Report of a WHO consultation. Geneva: World Health Organisation; 2000.

23. Shohaimi S, Luben R, Wareham N, Bingham S, Welch A, Oakes S, Khaw KT. Residential area deprivation predicts smoking habits independently of individual educational level and occupational social class. A cross sectional study in the Norfolk cohort of the European Investigation into Cancer (EPIC-Norfolk). J Epidemiol Community Health. 2003;57:270-6. 
24. Inter-Departmental Working Group. Sensible drinking London: Department of Health; 1995.

25. Hosmer D, Lemeshow S. Model-building Strategies and Methods for Logistic Regression, Applied Regression. New York: Wiley; 1989.

26. Boone-Heinonen J, Gordon-Larsen P, Guilkey DK, Jacobs DR Jr, Popkin BM. Environment and physical activity dynamics: The role of residential selfselection. Psychol Sport Exerc. 2011;12:54-60.

27. Costa S, Ogilvie D, Dalton A, Westgate K, Brage S, Panter J. Quantifying the physical activity energy expenditure of commuters using a combination of global positioning system and combined heart rate and movement sensors. Prev Med. 2015;81:339-44.

28. Yang L, Panter J, Griffin S, Ogilvie D. Associations between active commuting and physical activity in working adults: cross-sectional results from the Commuting and Health in Cambridge study. Prev Med. 2012;55:453-7.

29. Foster S, Knuiman M, Hooper P, Christian H, Giles-Corti B. Do changes in residents' fear of crime impact their walking? Longitudinal results from RESIDE. Prev Med. 2014;62:161-6.

30. Kerr Z, Evenson K, Moore K, Block R, Diez-Roux AV. Changes in walking associated with perceived neighborhood safety and police-recorded crime: The Multi-Ethnic Study of Atherosclerosis. Prev Med. 2015;73:88-93.

31. Farrall S, Bannister J, Ditton J, Gilchrist E. Questioning the measurement of the 'fear of crime'. Br J Criminol. 1997:37:658.

32. Jones CHD, Ogilvie D. Motivations for active commuting: a qualitative investigation of the period of home or work relocation. Int J Behav Nutr Phys Act 2012;9:109.

33. Guell C, Ogilvie D. Picturing commuting: photovoice and seeking wellbeing in everyday travel. Qual Res. 2015;15:201-18.

34. Beyer F, Ker K. Street lighting for preventing road traffic injuries. Cochrane Database Syst Rev. 2009;1:CD004728.

35. Welsh B, Farrington D. Effects of improved street lighting on crime. Campbell Sys Rev. 2008;13:1-51.

\section{Submit your next manuscript to BioMed Central and we will help you at every step:}

- We accept pre-submission inquiries

- Our selector tool helps you to find the most relevant journal

- We provide round the clock customer support

- Convenient online submission

- Thorough peer review

- Inclusion in PubMed and all major indexing services

- Maximum visibility for your research

Submit your manuscript at www.biomedcentral.com/submit
Biomed Central 